\title{
CARACTERIZAÇÃO MOLECULAR DE ESTAFILOCOCOS ISOLADOS DE VACAS COM MASTITE SUBCLÍNICA E ORDENHADORES
}

\author{
V.L.D.S. Fontana ${ }^{1}$, M.J.S.M. Giannini ${ }^{2}$, C.A.P. Fontana ${ }^{1}$, C.Q.F. Leite ${ }^{2}$, A.E. Stella ${ }^{1}$ \\ ${ }^{1}$ UniversidadeFederal deGoiás, Departamento de Medicina Veterinária, CP3, CEP75800-000, Jataí, GO, Brasil.
}

\author{
RESUMO
}

\begin{abstract}
As bactérias isoladas para o estudo foram oriundas de 96 vacas (163 tetos positivos no California Mastitis Test - CMT e nove suabes de mão de ordenhadores, de nove propriedades rurais situadas no Município de Jataí, GO. Das amostras coletadas (163 de leite e 9 de suabes de mão), foram identificadas 83 linhagens do gênero Staphylococcus spp., sendo S. aureus (31), S. saprophyticus (29), S. xylosus (17), S. epidermidis (4) e S. intermedius (2). No presente estudo, 35 perfis foram gerados de 83 amostras de Staphylococcus e o perfil IA (64,5\%) de S. aureus, IS (44,8\%) de S. saprophyticus, VX (35,3\%) de S. xylosus e IIE (50\%) de S. epidermidis foram os mais prevalentes. Houve predominância de um tipo entre os isolados de $S$. aureus nos rebanhos. Cepas idênticas foram encontradas em diferentes animais de uma mesma propriedade, assim como houve identidade genética entre cepa oriunda da mão do ordenhador e do animal. Assim, nossos dados mostraram que há variabilidade entre os isolados, mas também similaridade genética de algumas cepas concentradas em determinados locais. A similaridade genética pode compreender um complexo de clones relacionados, sugerindo relação de contaminação e transferência cruzada entre as cepas de origem humana e animal.
\end{abstract}

PALAVRAS-CHAVE: Mastite bovina subclínica, Staphylococcus, RAPD-PCR.

\section{ABSTRACT}

MOLECULAR CHARACTERIZATION OF STAPHYLOCOCCI ISOLATED FROM BOVINE MASTITIS AND MILKING WORKERS. Bacteria isolated for this study were derived from 96 cows (163 quarters positive for the California Mastitis Test (CMT) and 9 swabs taken from the hands of milking staff, on 9 farms in the municipality of Jataí, state of Goiás, Brazil. Of the samples collected ( 163 from milk and 9 swabs taken from hands) 83 strains of the genus Staphylococcus spp. were identified: S. aureus (31), S. saprophyticus (29), S. xylosus (17), S. epidermidis (4), S. intermedius (2). In this study, 35 profiles were generated from 83 samples of Staphylococcus, and profile IA (64.5\%) of S. aureus, IS (44.8\%) of S. Saprophyticus, VX (35.3\%) of S. xylosus and IIE (50\%) of S. epidermidis were the most prevalent. There was a predominance of one type among isolates of $S$. aureus in herds. Identical strains were found in different animals of the same farm, as well as genetic identity between the strain isolated from the hand of the milker and the animal. Thus, our data showed that there is variability among isolates, but also genetic similarity of some strains concentrated in certain locations. The genetic similarity may comprise a complex of related clones, suggesting a relationship of cross-contamination and transfer among strains of human and animal origin.

KEY WORDS: Subclinical bovine mastitis, Staphylococcus spp., RAPD-PCR.

\section{INTRODUÇÃO}

A mastite bovina é uma enfermidade complexa, resultando de interações entre hospedeiro, ambiente e micro-organismo. Usualmente, a doença é provocada por uma variedade de patógenos que apresentam diferenças na virulência e patogenicidade. Apesar de melhorias em gerenciamento de saúde do úbere, Staphylococcus sp. ainda persiste como gênero primário e em um grande número de fazendas. Dentro deste gênero, Staphylococcus aureus é reconhecido como o principal patógeno da mastite bovina e seus principais sítios de localização nos animais parecem ser os quartos infectados (ZAFALON et al., 1999). Esta espécie também é um agente de intoxicação no homem e tem sido relatada em vários surtos de doenças transmissíveis por alimentos (LAMAITA et al., 2005), bem como pode ser veiculada pelas mãos dos ordenhadores (ZADOKS et al., 2002).

Entretanto,Staphylococcus sp. coagulase negativos (SCN) têm se tornado os isolados mais comumente encontrados na mastite bovina em muitos países e

${ }^{2}$ Universidade Estadual Paulista, Faculdade de Ciências Farmacêuticas, Departamento de Análises Clínicas, Araraquara, SP, Brasil. 
poderiam, portanto, ser descritos como patógenos emergentes da mastite, principalmente como causadores de mastite subclínica persistente (PYorala; TAPONEn, 2009). Dentreestas espécies, o Staphylococcus epidermidis (THORBERG et al., 2006), S. saprophyticus, S. xylosus e S. intermedius (Moon et al., 2007) já foram relatadoscomoagentes causadores de mastite bovina. Além disso, osSCN podem apresentar umalto grau de resistência aos antimicrobianos (MAcHADOetal., 2008).

O rápido isolamento e caracterização dos estafilococos, de vacas e novilhas, é fundamental para evitar a propagaçãodestes agentes no rebanhoe, consequentemente, a implantação de um controle bem sucedido da doença (ZADOKs et al., 2002). Uma vez identificado o agente, marcadores epidemiológicos podem ser capazes de discriminar isoladosnão relacionadosemum mesmo grupo epidemiológico. Estes estudos são para melhor delinear o papel de alguns micro-organismos e incrementar métodos de controle.

O objetivo do presente estudo é de fazer a caracterização molecular de cepas mais frequentemente isoladas do gênero Staphylococcus de mastite subclínica bovina e mãos dos ordenhadores, através da técnica de RAPD-PCR, verificando o grau de similaridade dos isolado.

\section{MATERIAL E MÉTODOS}

\section{Isolamento bacteriano}

As bactérias isoladas para o estudo foram oriundas de 96 vacas [163 tetos positivos no California Mastitis Test - CMT de acordo com Schalm; Noorlander (1957)] e de nove suabes de mão de ordenhadores, de nove propriedades rurais situadas no Município de Jataí, GO. Em tubos estéreis, foram colhido $20 \mathrm{~mL}$ de leite após a lavagem e desinfecção dos tetos com álcool iodado a 3\%, desprezando-se os três primeiros jatos. As amostras das mãos dos ordenhadores foram obtidas com suabes estéreis como descrito por NISHIJIMA et al. (1997). Após as coletas, os materiais foram acondicionados em caixas isotérmicas com gelo e levados ao laboratório de Microbiologia da UniversidadeFederal deGoiás, Campus de Jataí. Utilizaram-se para cultivo e identificação dos micro-organismos, meios de cultura e testes convencionais (crescimento em agar furazolidona e agar sangue, hemólise, catalase, coagulase, redução de nitrato, fermentação da frutose, manitol, trealose, manose, sacarose, rafinose, salicina e resistência a novobiocina e bacitracina) de identificação bacteriana segundoKonEMANetal.(2001).

\section{Extração e purificação do DNA genômico}

Para a extração do DNA genômico dos isolados de Staphylococcus foi utilizado o Kit GFX ${ }^{\mathrm{TM}}$ Genomic
Blood - DNA Purification. Uma densa suspensão de cada isolado foi transferida para placas com Agar Muller Hinton e incubadas a $37^{\circ} \mathrm{C}$ por 24 horas. Após a incubação, três colônias puras foram repicadas para o meio infusão de cérebro - coração (BHI) e mantidas a $37^{\circ} \mathrm{C} / 24$ horas sob agitação. Em seguida, o DNA foi extraído conforme recomendação do fabricante. A concentração foi determinada em espectrofotômetro em $260 \mathrm{~nm}$ e o DNA foi estocado a $-20^{\circ} \mathrm{C}$.

\section{Reação de RAPD-PCR}

\section{RAPD-PCR}

A tipagem molecular das cepas foi realizada pelo método de RAPD ("Randon Amplified Polymorphyc DNA") utilizando o Kit Ready-To-Go/ RAPD Analysis Beads (Amersham Pharmacia Biotech). Oitenta e três isolados de Staphylococcus sp. foram analisados tanto de vacas leiteiras com mastite subclínica como das mãos dos ordenhadores.

Ensaios preliminares foram realizados com algumas amostras escolhidas aleatoriamente para testar as sequências iniciadoras mais adequadas. Para tanto, foram comparadas as sequências iniciadoras: 1 - (5 -d(GGTGCGGAA)-3) e 2-(5-d(GTTTCGCTCC)-3). Após análise prévia, todas as amostras foram amplificadas com a sequência 1 . Reagentes e condições foram utilizados de acordo com o fabricante, onde a amplificação foi realizada através de um ciclo inicial com temperatura de desnaturação de $95^{\circ} \mathrm{C}$ por 5 minutos, seguido de 45 ciclos de $95^{\circ} \mathrm{C}$ por 1 minuto, $36^{\circ} \mathrm{C}$ por 1 minuto e $72^{\circ} \mathrm{C}$ por 2 minutos.

\section{Eletroforese do DNA amplificado}

Os "amplicons" foram separados por eletroforese em gel de agarose a 2\% (Gibco) em tampão TBE $1 X$ durante 2 horas e 30 minutos a 150 volts. Os produtos da amplificação (5 microlitros) foram misturados com 10 microlitros de tampão de amostra (glicerol 30\%, EDTA $100 \mathrm{mM} \mathrm{pH} \mathrm{8,0,} \mathrm{azul} \mathrm{de} \mathrm{bromofenol} \mathrm{0,30 \% )}$ e aplicados nos poços de gel. Como padrão do peso molecular foi usado 100 pb "Ladder" (Gibco - BRL). Os "amplicons" no gel foram corados pelo brometo de etídio (Gibco - BRL) na concentração de $0,5 \mathrm{ug} / \mathrm{mL}$, visualizados a luz ultravioleta e fotodocumentados.

\section{Construção de dendrogramas (Determinação da Similaridade)}

Para o cálculo da matriz de similaridade foi utilizado o coeficiente de Jaccard. A análise do bandeamento produzido por cada sistema estirpe gerou uma matriz binária, que foi analisada pelo programa deSistema da Análise Multivariada (NTSYS - pc). O dendrograma foi construído pelo método de agrupamento hierárquico UPGMA (“Unweighted Pair Group Method with Arithmetic Mean"), através do 
programa SAHN do NTSYS (Numerical Taxonomy and Multivariated Analysis System) (RoHLF; SLICE, 1992), que compara as estirpes, duas a duas, agrupando de forma tanto mais similar quanto mais coincidentes forem os fragmentos de mesma massa molecular.

\section{RESULTADOS}

\section{Espécies de Staphylococcus isoladas do leite}

Das amostras coletadas ( 163 de leite e 9 de suabes de mão) foram identificadas 83 linhagens do gênero Staphylococcus, sendo S. aureus (31), S. saprophyticus (29), S. xylosus (17), S. epidermidis (4) e S. intermedius (2). Em algumas propriedades observou-se prevalência de uma única espécie de Staphylococcus sugerindo manejo higiênico-sanitário inadequado ou a presença de mecanismos de competição entre os micro-organismos. A espécie mais isolada foi $S$. aureus, sendo mais prevalente na propriedade 8 . As espécies de Staphylococcus coagulase negativas ( $S$. saprophyticus, S. xylosus, S. epidermidis) foram mais frequentes em relação às espécies de Staphylococcus coagulase positivas (S. aureus e $S$. intermedius).
Foram isolados Staphylococcus spp. das mãos dos ordenhadores:3 Staphylococcus aureus (propriedade7, 8 e 9), 1 Staphylococcus saprophyticus (propriedade 5). Na Tabela1 são correlacionados os micro-organismos isolados das amostras de leite e das mãos dos ordenhadores de acordo com as propriedades.

Análise dos perfis genotípicos das espécies de Staphylococcus por RAPD-PCR e dendrograma

Utilizando-se a sequência iniciadora 1,35 padrões genotípicos foram obtidos, com número de bandas variando de 3 a 13, de 1900 a 180 pb (Tabela 2).

A análise dos perfis genotípicos das amostras, gerados pela variação da região do DNA amplificada, revelou considerável heterogeneidade entre os isolados de mesma espécie. Padrões genotípicos foram distintos entre os 31 isolados de $S$. aureus e padrões de 5 a 10 bandas foram gerados, apresentando 10 perfis diferentes, denominados de IA a XA, distribuindo-se da seguinte forma: perfil IA $(5,9,68,79,95,108,109$, 110, 111, 112, 113, 123, 126, 131, 132, 134, 137 (O), 138 (O), 30, 67, onde "O" significa amostra humana); IIA (115 O); IIIA (119); IVA (128); VA (130); VIA (89); VIIA (13 e 24); VIIIA (7 e 10); IXA (6) e XA (8), sendo o perfil IA o predominante.

Tabela 1 - Distribuição das espécies de Staphylococcus sp. isoladas do leite e mão dos ordenhadores por propriedade.

\begin{tabular}{|c|c|c|c|c|c|c|c|c|c|c|c|}
\hline \multirow{2}{*}{$\mathrm{P}$} & \multicolumn{2}{|c|}{ S. aureus } & \multicolumn{2}{|c|}{ S. saprophyticus } & \multicolumn{2}{|c|}{ S. xylosus } & \multicolumn{2}{|c|}{ S. epidermidis } & \multicolumn{2}{|c|}{ S. intermedius } & \multirow{2}{*}{$\begin{array}{c}\text { Total } \\
\text { propriedade }\end{array}$} \\
\hline & Leite & Mão & Leite & Mão & Leite & Mão & Leite & Mão & Leite & Mão & \\
\hline 1 & 01 & 0 & 0 & 0 & 04 & 0 & 0 & 0 & 0 & 0 & 05 \\
\hline 2 & 0 & 0 & 0 & 0 & 13 & 0 & 0 & 0 & 0 & 0 & 13 \\
\hline 3 & 0 & 0 & 15 & 0 & 0 & 0 & 0 & 0 & 0 & 0 & 15 \\
\hline 4 & 0 & 0 & 08 & 0 & 0 & 0 & 0 & 0 & 0 & 0 & 08 \\
\hline 5 & 0 & 0 & 05 & 01 & 0 & 0 & 0 & 0 & 0 & 0 & 06 \\
\hline 6 & 02 & 0 & 0 & 0 & 0 & 0 & 4 & 0 & 2 & 0 & 08 \\
\hline 7 & 06 & 01 & 0 & 0 & 0 & 0 & 0 & 0 & 0 & 0 & 07 \\
\hline 8 & 13 & 01 & 0 & 0 & 0 & 0 & 0 & 0 & 0 & 0 & 14 \\
\hline 9 & 06 & 01 & 0 & 0 & 0 & 0 & 0 & 0 & 0 & 0 & 07 \\
\hline $\mathrm{T}$ & 28 & 03 & 28 & 01 & 17 & 0 & 4 & 0 & 2 & 0 & 83 \\
\hline
\end{tabular}

P: Propriedade, T: total.

Tabela 2 - Perfis genotípicos das espécies isoladas de Staphylococcus.

\begin{tabular}{lcc}
\hline Espécies isoladas & № de bandas & № perfis genotípicos \\
\hline S. aureus (31) & 5 a 10 & 10 \\
S. saprophyticus (29) & 3 a 13 & 12 \\
S. xylosus (17) & 6 a 11 & 9 \\
S. epidermidis (4) & 7 a 8 & 3 \\
S. intermedius (2) & 3 a 4 & 1 \\
\hline
\end{tabular}


Tabela 3 - Valores de coeficientes de similaridade observados em diferentes cepas.

\begin{tabular}{lcc}
\hline Espécies isoladas & Cepas & Coeficiente de similaridade \\
\hline S. epidermidis & 2 e 3 & 0,32 \\
S. saprophyticus & 26 e 27 & 1,00 \\
& 20 e 29 & 0,90 \\
S. xylosus & 75 e 76 & 0,80 \\
S. intermedius & 35 e 41 & 1,00 \\
S. aureus & 64 e 65 & 0,75 \\
& 55 e 127 & 0,32 \\
\hline
\end{tabular}

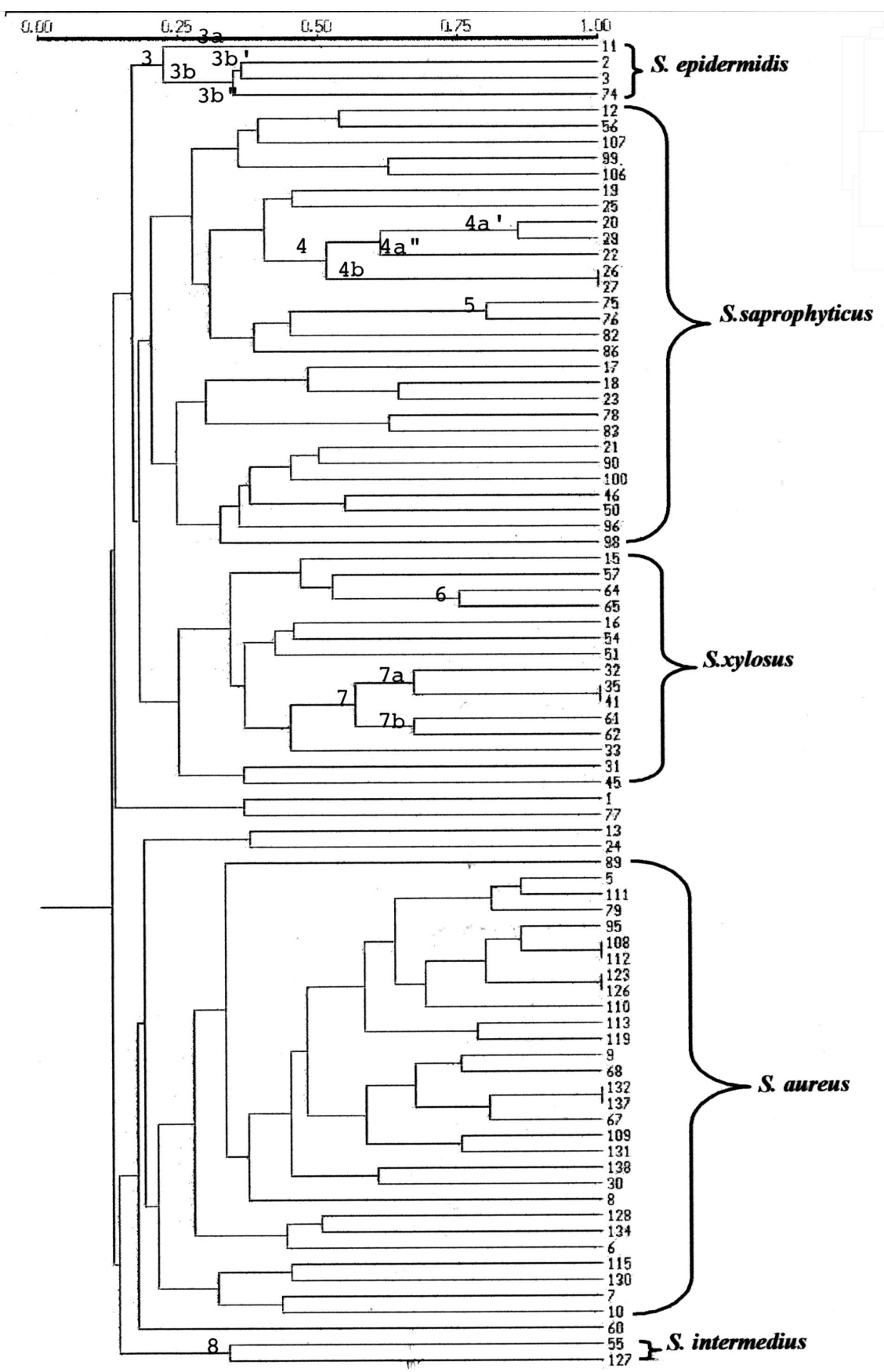

Fig.1 - Dendograma de todas as espécies de Staphylococcus sp. 


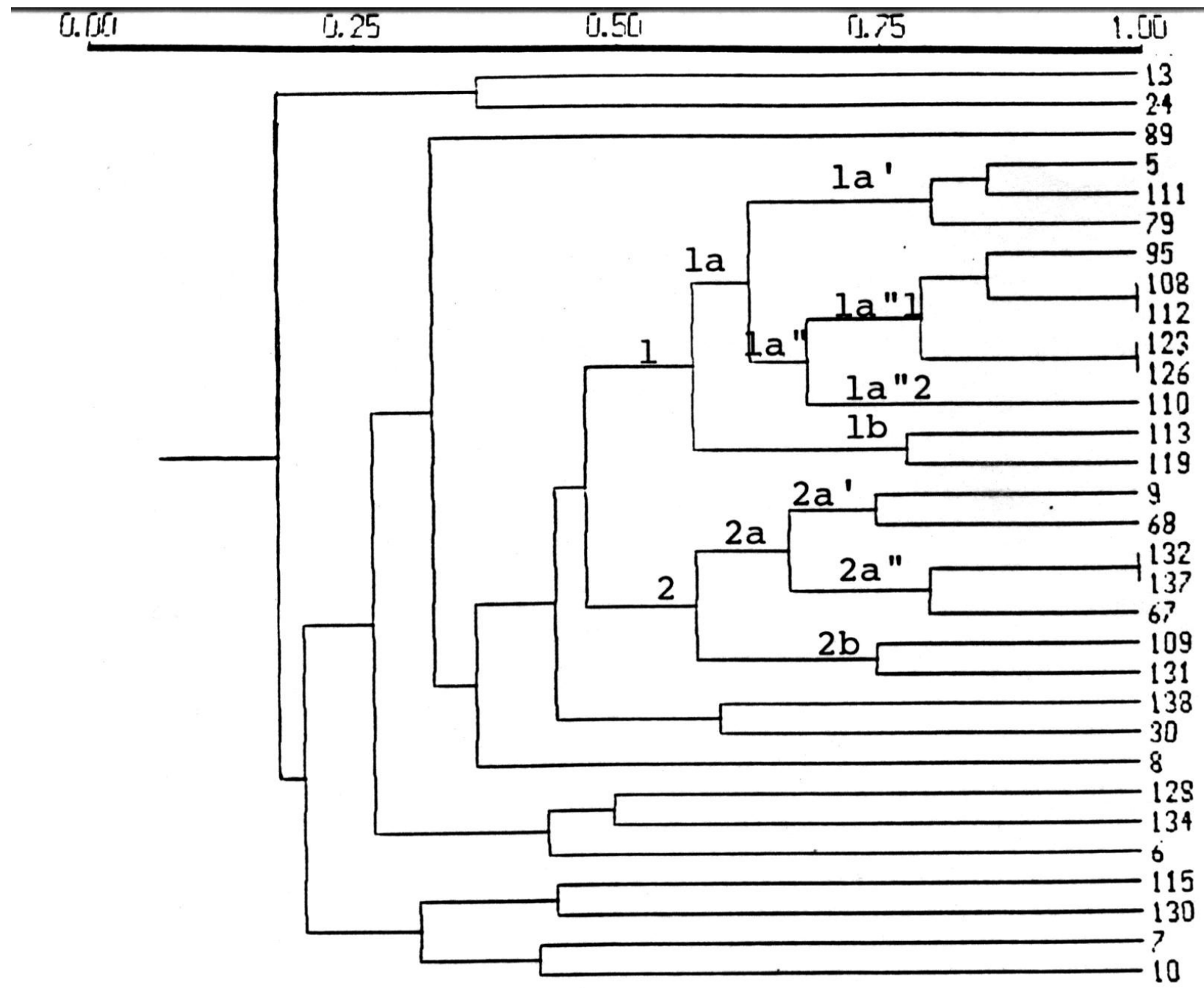

Fig. 2 - Dendrograma das amostras de S. aureus de diferentes propriedades.

Para as amostras isoladas de S. saprophyticus, houve a diferenciação em 12 perfis diferentes denominados IS a XIIS, distribuindo-se da seguinte forma: perfil IS ( $20,22,26,27,29,75,76,83,86,98$, 99, 106 e 107); IIS (82); IIIS (78); IVS (12, 17, 18, 23 e 56); VS (19); VIS (21); VIIS (25); VIIIS (60 O); IXS (46 e 50); XS (90); XIS (96) e XIIS (100), sendo o perfil IS o predominante.

O dendrograma de todas as espécies de Staphylococcus sp., resultantes da análise dos fragmentos de DNA, está apresentado na Figura 1. Foi observado que os valores dos coeficientes de similaridade em diferentescepas de todas as espécies de Staphylococcus apresentam grande distância genética, e que algumas cepas, principalmente de $S$. aureus, apresentaram coeficiente de similaridade igual a 1,0 (Tabela 3).

Odendrograma das amostras de S. aureus baseado em coeficiente de similaridade entre todos os pares está apresentado nas Figuras 1 e 2. O limiar inicial para discriminar os grupos foi de 0,68 e o coeficiente de similaridade 1,0 representa cepas idênticas. Dos
31 isolados, 11 estavam agrupados em um único grupo clonal, o qual foi denominado 1 . O subtipo 1 a' apresentava as cepas 5 e 111 que tinham índice de similaridade maior que 0,80 e amostra 79 em torno de 0,80 . No subtipo 1 a"1 estavam agrupadas duas cepas 108 e 112 com coeficiente de similaridadeigual a 1,0, como também as cepas 123 e 126 . As cepas 108, 112,123 e 126 oriundas da mesma propriedade e com coeficiente de similaridade igual a 1,0 sugerem origem clonal comum. O outro grupo clonal distinto foi denominado de 2 e possuía 7 isolados. O subtipo $2 \mathrm{a}$ " apresentava cepas pertencentes à propriedade 9 (132 e 137 [O]) que tinham índice de similaridade igual a 1,0, sugerindo uma provável origem clonal comum.

A cepa de número 137 de $S$. aureus da mão do ordenhador e a cepa 132 de $S$. aureus de uma vaca apresentaram coeficiente de similaridade igual a 1, sugerindo ser da mesma origem clonal, no entanto, as demais cepas apresentaram índices de similaridade baixos, indicando não haver relação entre elas (Fig. 2). 


\section{DISCUSSÃO}

A mastite subclínica reveste-se de grande importância em nosso meio, tanto pelas perdas econômicas como pela problemática relacionada à saúde pública. Os estudos brasileiros realizados nos últimos anos tiveram aumento significativo, porém, centralizaram-se na região Sul e Sudeste. Assim, neste trabalho procurou-se estudar o assunto à luz de técnicas clássicas e moleculares empregando amostras da região Centro-Oeste. Admite-se que a alta prevalência da doença encontrada deve-se ao tipo de manejo utilizado pelos criadores, ordenha manual com escassos cuidados higiênico-sanitários, além de não serem adotados programas de controle para a mastite.

A partir das 163 amostras de leite positivas ao C.M.T., S. aureus (28) e S. saprophyticus (28) foram as espécies mais isoladas, seguidas pelo $S$. xylosus (17), S. epidermidis (4) e S. intermedius (2). Resultado semelhante ao encontrado por ANDRADE (2001) onde o S. aureus foi isolado de 30,2\% de 667 amostras de leite provenientes de vacas em lactação com mastite subclínica, em 25 propriedades leiteiras do Estado de Goiás.

A grande frequência de isolamento de $S$. aureus revela a importante dispersão cosmopolita deste micro-organismo nos rebanhos bovinos. Destaca-se o isolamento de $28 \mathrm{~S}$. saprophyticus, agente pouco relatado em mastite subclínica. Esta espécie representou a maioria dos SCN, cuja importância vem sendo reconhecida na etiologia da mastite bovina como micro-organismos emergentes causadores de mastite subclínica de forte impacto econômico (PYORALA; TAPONEn, 2009). Os SCN são responsáveis pelas elevadas contagens de células e pela diminuição na produção de leite.

$S$. aureus foi o micro-organismo mais isolado tanto das mãos dos ordenhadores como também de amostras de leite, fato este justificado em outros estudos em que a glândula mamária é considerada o reservatório primário de mastite por $S$. aureus. Observa-se que existiu certa correlação entre os micro-organismos isolados das mãos dos ordenhadores e das amostras de leite das mesmas propriedades (Tabela 1).

A diferenciação de cepas é de grande importância noestudoepidemiológico deenfermidadesinfecciosas e o advento da biologia molecular tem possibilitado a caracterização de pontos distintos na cadeia de transmissão dessas enfermidades (VIEIRA-DA-MotA et al., 2001). Os métodos de tipagem devem ser capazes de distinguir a mesma cepa em isolados independentes, agrupar isolados geneticamente relacionados e identificar os não relacionados geneticamente. A partir desses resultados, pode-se determinar marcadores epidemiológicos que servirão para a investigação da presença e/ou disseminação de cepas de estafilocococos de origem humana e animal.

Neste trabalho, para a tipificação de S. aureus e de outros estafilococos foi empregada a técnica derivada do PCR. Conforme LipMan et al. (1996), o método de RAPD-PCR para diferenciação genotípica de cepas de $S$. aureus foi mais adequado que a fagotipagem.

No presente estudo, 35 perfis foram gerados de 83 amostras de Staphylococcus, sendo que o perfil IA $(64,5 \%)$ de $S$. aureus , o IS $(44,8 \%)$ de $S$. saprophyticus e o VX $(35,3 \%)$ de S. xylosus e IIE (50\%) de S.epidermidis foram os mais prevalentes. O perfil IA de $S$. aureus foi principalmente encontrado nas propriedades 7 , 8 e 9 , o perfil IS de $S$. saprophyticus foi oriundo das propriedades 3, 4 e 5 e o perfil VX de S. xylosus da propriedade 7 . Verifica-se que há predominância de um único tipo $(64,5 \%)$ entre os isolados de $S$. aureus e isto poderia ser atribuído à contagiosidade do patógeno, indicando disseminação da infecção, também que poucas cepas têm características para causar mastite e uma terceira possibilidade é que cepas patogênicas geneticamente diferentes têm porções do DNA equivalentes e não diferenciáveis por RAPD.

No controle da mastite é fundamental que a origem dos agentes infectantes seja identificada. Embora a avaliação do estado de portador em humanos como fonte de infecção já tenha sido relatada (LARSEN et al., 2000), e técnicas moleculares para tipagem de cepas de $S$. aureus de casos de mastite bovina (LANGE et al., 1999) tenham sido descritas, os estudos moleculares direcionados à caracterização da relação epidemiológica entre cepas de $S$. aureus isoladas de locais apontados como prováveis fontes de transmissão deste patógeno têm sido pouco explorados.

S. aureus é relacionado como um dos patógenos contagiosos e a exposição de quartos mamários não infectados é limitada ao processo de ordenha. As principais fontes de infecção são os quartos mamários infectados, a pele do úbere e dos tetos, da mesma forma que as mãos e/ou bocais da ordenhadeira são considerados potenciais vias de transmissão da infecção. Assim, os portadores humanos podem constituir-se em fonte de novas cepas em infecções de rebanhos individuais. Neste estudo, algumas cepas de $S$. aureus apresentaram coeficiente de similaridade igual a 1,0, sugerindo uma provável origem clonal. Cepas idênticas foram encontradas em diferentes vacas de uma mesma propriedade, sugerindo disseminação da infecção. Por outro lado, ficou demonstrado que, aparentemente, em um dos casos, a fonte de contaminação provável foi a mão do ordenhador, pois, dentro da mesma propriedade houve identidade genética entre a cepa oriunda do animal e do homem, resultado similar ao encontrado por Neves et al. (2010). Entretanto, a mesma origem clonal ter sido encontrada na mão do ordenhador 
não significa necessariamente que esta é a origem da contaminação do úbere. É possível o trajeto inverso, ou seja, do úbere para a mão do ordenhador. LARSEN et al. (2000) relataram estreita relação entre cepas de S. aureus isoladas de casos de infecção intramamária em vacas e em lesões de pele desses animais, no entanto, as amostras isoladas dos ordenhadores foram distintas dos isolados de origem animal.

\section{CONCLUSÕES}

Os ensaios de RAPD conduzidos foram de grande utilidade como instrumento de estudoepidemiológi$\mathrm{co}$, visto que apresentaram poder discriminatório. Foi possível determinar 35 perfis genotípicos diferentes de83 amostras de Staphylococcus sp. Há variabilidade genética entre os isolados, mas também identidade genotípica de algumas cepas sugerindo a presença decepas epidêmicas de $S$. aureus nos rebanhos, assim como houveidentidade entre cepas de origem animal ehumana (mão do ordenhador), fortalecendo o papel do portador humano como fonte de contaminação na mastite bovina.

\section{AGRADECIMENTOS}

À FAPESP, pelo auxílio financeiro ao trabalho e aos produtores rurais pela colaboração na coleta de amostras.

\section{REFERÊNCIAS}

ANDRADE, M.A. Mastite bovina subclínica: prevalência, etiologia e testes de sensibilidade a drogas antimicrobianas. A Hora Veterinaria, v.20, n.119, p.19-26, 2001.

KONEMAN, E.W.; ALLEN, S.D.; JANDA, W.M.; SCHRECKENBERGER, P.C.; WINN JUNIOR, W.C. Diagnóstico microbiológico. Texto e Atlas Colorido. 5 ed. Rio de Janeiro: MEDSI, 2001. 1465p.

LAMAITA, H.C.; CERQUEIRA, M.M.O.P.; CARMO, L.S.; SANTOS, D.A.; PENNA, C.F.A.M.; SOUZA, M.R. Staphylococcus sp. counting and detection of staphylococcal enterotoxins and toxic shock toxin syndromefrom cooled raw milk. Arquivo Brasileiro de Medicina Veterinaria e Zootecnia, v.57, p.702-709, 2005.

LANGE, C.; CARDOSO, M.; SENCZEK, D.; SCHWAR, S. Molecular subtyping of Staphylococcus aureus isolates from cases of bovine mastitis in Brazil. Veterinary Microbiology, v.67, p.127-141, 1999.

LARSEN, H.D.; SLOTH, K.H.; ELSBERG, C.; ENEVOLDSEN, C.; PEDERSEN, L.H.; ERIKSEN, N.H.R.; AARESTRUP, F.M.; JENSE, N.E. The dynamics of
Staphylococcus aureus intramammary infection in nine Danish dairy herds. Veterinary Microbiology, v.71, n.1/2, p.89-101, 2000.

LIPMAN, L.J.A.; NIJS, A.; LAM, T.J.G.M.; ROST, J.A.; VAN DIJK, L.; SCHUKKEN, Y.H.; GAASTRA, W. Genotyping by PCR of Staphylococcus aureus strains, isolated from mammary glands of cows. Veterinary Microbiology, v.48, p.51-55, 1996.

MACHADO, T.R.O.; CORREA, M.G.; MARIN, J.M. Antimicrobial susceptibility of coagulase-negative Staphylococci isolated from mastitic cattle in Brazil. Arquivo Brasileiro de Medicina Veterinaria e Zootecnia, v.60, n.1, p.278-282, 2008.

MOON, J.S.; LEE, A.R.; KANG, H.M.; LEE, E.S.; KIM, M.N.; PAIK, Y.H.; PARK, Y.H.; JOO, Y.S.; KOO, H.C. Phenotypic and Genetic Antibiogram of MethicillinResistant Staphylococci Isolated from Bovine Mastitis in Korea. Journal of Dairy Science, v.90 n.3, 2007.

NEVES, M.C.; COSTA, J.R.V; VIEIRA, V.C; ABREU, I.L; LEMOS, M.V.F. Resistência aos antimicrobianos e análise da diversidade genética de Staphylococcus aureus por PCR-RAPD. Arquivos do Instituto Biológico, São Paulo, v.77, n.4, p.575-582, 2010. Disponível em: <http://www.biologico.sp.gov.br/docs/arq/v77_4/ neves.pdf $>$.

NISHIJIMA, S.; NAMURA, S.; HIGASHIDA T.; KAWAI $\mathrm{S}$. Staphylococcus aureus in the interior nares and subungual spaces of the hands in atopic dermatitis. Journal of International Medical Research, v.25, p.155-158, 1997.

PYORALA, S.; TAPONEN, S. Coagulase-negative staphylococci - emerging mastitis pathogens. Veterinary Microbiology, v.134, p.1-2, 2009.

ROHLF, F.J.; SLICE, D.E. Numerical taxonomy and multivariate analysis system. New York: Exater Software, 1992. $115 p$.

SCHALM, O.W.; NOORLANDER, D.O. Experiments and observations leading to development of the California Mastitis Test. Journal of the American Veterinary Medical Association, v.130, n.5, p.199-204, 1957.

THORBERG, B.M.; KUHN, I.; AARESTRUP, F.M.; BRANDSTROM, B.; JONSSON, P.; NIELSSON-THAM, M.L. Pheno and genotyping of Staphylococcus epidermidis isolated from bovine milk and human skin. Veterinary Microbiology, v. 115, p.163-172, 2006.

VIEIRA-DA-MOTA, O.; FOLLY, M.M.; SAKYIAMA, C.C.H. Detection of different Staphylococcus aureus strains in bovine milk from subclinical mastitis using PCR and routine techniques. Brazilian Journal of Microbiology, v.32, n.1, p.1-9, 2001.

ZADOKS, R.N.; ALLORE, H.G.; HAGENAARS, T.J.; BARKEMA, H.W.; SCHUKKEN, Y.H. A mathematical 
model of Staphylococcus aureus control in dairy herds. Epidemiology and Infection, v.129, p.397-416, 2002.

ZAFALON, L.F.; AMARAL, L.A; NADER FILHO, A.; OLIVEIRA, J.V. Influência de bactérias do gênero Corynebacterium e estafilococos coagulase positivos e negativos sobre a contagem de células somáticas e a produção láctea de quartos mamários com mastite subclínica. Napgama, v.2, n.6, p.4-6, 1999.

Recebido em 11/10/11

Aceito em 15/10/12 